Article

\title{
Grip Strength: A Useful Marker for Composite Hepatic Events in Patients with Chronic Liver Diseases
}

\author{
Kazunori Yoh ${ }^{1, \dagger}$, Hiroki Nishikawa ${ }^{1,2,+, *}$, Hirayuki Enomoto ${ }^{1}$, Yoshinori Iwata ${ }^{1}$, Naoto Ikeda ${ }^{1}$, \\ Nobuhiro Aizawa ${ }^{1}$, Takashi Nishimura ${ }^{1}$, Hiroko Iijima ${ }^{1}$ and Shuhei Nishiguchi ${ }^{1}$ \\ 1 Division of Hepatobiliary and Pancreatic disease, Department of Internal Medicine, Hyogo College of \\ Medicine, Nishinomiya, Hyogo 663-8501, Japan; mm2wintwin@ybb.ne.jp (K.Y.); \\ enomoto@hyo-med.ac.jp (H.E.); yo-iwata@hyo-med.ac.jp (Y.I.); nikeneko@hyo-med.ac.jp (N.I.); \\ nobu23hiro@yahoo.co.jp (N.A.); tk-nishimura@hyo-med.ac.jp (T.N.); hiroko-i@hyo-med.ac.jp (H.I.); \\ nishiguc@hyo-med.ac.jp (S.N.) \\ 2 Center for Clinical Research and Education, Hyogo College of Medicine, Nishinomiya, \\ Hyogo 663-8501, Japan \\ * Correspondence: nishikawa_6392_0207@yahoo.co.jp; Tel.: +81-798-45-6111; Fax: +81-798-45-6608 \\ + These authors contributed equally to this work.
}

Received: 30 March 2020; Accepted: 17 April 2020; Published: 20 April 2020

\begin{abstract}
Here we sought to clarify the prognostic impact of sarcopenia-related markers (grip strength (GS), muscle mass using bioimpedance analysis and patient quality of life as assessed by the 36-Item Short-Form Health Survey (SF36)) in patients with chronic liver diseases (CLDs, $n=411 ; 160$ liver cirrhosis patients; median age, 64 years) on the incidence of composite hepatic events (CHEs). A GS decrease was defined as $<26 \mathrm{~kg}$ in men and $<18 \mathrm{~kg}$ in women, while a skeletal muscle mass index (SMI) decrease was defined as $<7.0 \mathrm{~kg} / \mathrm{m}^{2}$ in men and $<5.7 \mathrm{~kg} / \mathrm{m}^{2}$ in women based on the current guidelines. The physical and metal component summary scores on the SF36 were also included into the analysis. Sixty-two patients $(15.1 \%)$ had the first incidence of CHEs. The three-year cumulative incidence rates of CHEs in patients with GS decrease or non-decrease were $24.51 \%$ and $12.44 \%(p=0.0057)$. The three-year cumulative incidence rates of CHEs in patients with an SMI decrease or non-decrease were $19.65 \%$ and $12.99 \%(p=0.0982)$. Multivariate analysis revealed that GS decrease $(p=0.0350)$ and prothrombin time $(p=0.0293)$ were significantly associated with the incidence of CHEs. In conclusion, GS can be an independent predictor for CHE development in patients with CLDs.
\end{abstract}

Keywords: chronic liver disease; composite hepatic events; grip strength; muscle mass; quality of life; predictor

\section{Introduction}

Skeletal muscle is crucial for mobility, regulating the metabolism of glucose and fats, cardiopulmonary function, immune function, cytokine balance, and activities of daily life [1,2]. Sarcopenia, as defined by decreased muscle strength and a muscle mass decline, is a common syndrome in patients with chronic liver diseases (CLDs) due to the disease burden itself (i.e., secondary sarcopenia) [3-6]. Physical activity and quality of life (QOL) are also likely to be impaired in CLD patients with sarcopenia due to skeletal muscle mass loss and muscle contractile dysfunction $[7,8]$. Lifestyle and physical health in early life can be long-term determinants of a muscle strength decline [9]. Several previous reports highlighted the importance of improving QOL in patients with CLDs [10-14]. We previously demonstrated that grip strength (GS) was closely linked to health-related QOL as assessed by the 36-Item Short-Form Health Survey (SF36) in patients with CLDs [15]. A recent 
meta-analysis reported that sarcopenia may be associated with higher mortality in CLD patients [3]. Combined Model for End-Stage Liver Disease (MELD) and sarcopenia are associated with improved predictability for mortality in patients with liver cirrhosis (LC), mainly in those with low MELD scores [16]. Sarcopenia has been gaining much attention these days in numerous chronic diseases and malignancies as well as in elderly persons [4,5,17-19]. However, which of the sarcopenia-related factors (GS, muscle mass, or patient QOL) is most likely associated with clinical outcomes in CLD patients remains unsolved. Elucidating this point is of clinical importance for establishing the appropriate interventional strategies in CLD patients.

Considering clinical outcomes in patients with CLDs, composite hepatic events (CHEs), which involve hepatic decompensation, new-onset or deterioration of ascites, variceal bleeding, acute-on-chronic liver failure, hepatic encephalopathy (HE), and hepatocellular carcinoma (HCC), have been extensively used to assess the outcomes of patients with CLDs [20-24]. These events are well-known predictors for survival in CLDs [25-30]. Composite study endpoints are preferentially used, mainly in the field of cardiac diseases [31-33]. However, the prognostic impact of sarcopenia-related markers in patients with CLDs on CHEs remains unclear. In this study, we sought to clarify those essential research issues.

\section{Patients and Methods}

\subsection{Patients}

A total of 411 individuals with CLD who were admitted to Hyogo College of Medicine Hospital, Japan, between December 2013 and March 2019 were consecutively enrolled. Data for muscle strength as evaluated by GS, bioimpedance analysis (BIA; data for muscle mass), and SF36 scores were collected. There was no clear evidence of HCC in any patients on baseline radiology.

During the follow-up period, hematological and radiologic tests for identifying HCC incidence or liver-related complications were performed every 3-6 months. LC or non-LC was determined according to pathological data, imaging findings (presence of liver deformity, splenomegaly, or varices) and/or laboratory data [34-36]. In cases of a serum albumin level falling to less than $3.5 \mathrm{~g} / \mathrm{dL}$, nutritional interventions such as branched-chain amino acid therapies were considered [37,38]. In cases of hepatitis C virus (HCV) or hepatitis B virus (HBV), antiviral treatments were also considered [37]. Alcoholic liver disease patients were instructed to stop all alcohol intake. For patients with other liver disease etiologies, the most adequate intervention for each underlying liver disease was provided. The diagnosis of any CHE was determined based on the current guidelines; in cases of CHE incidence, an appropriate therapy was provided according to the current guidelines $[27,29,30,39,40]$. No patients underwent liver transplantation during the observation period.

The current study protocol conformed to the 1975 Helsinki Declaration, and ethical approval was obtained from the institutional review board in the Hyogo College of Medicine Hospital. All personal information was protected.

\subsection{GS and Skeletal Muscle Mass Index}

Baseline GS and skeletal muscle mass index (SMI) using BIA (calculated by appendicular muscle mass divided by height squared $\left(\mathrm{kg} / \mathrm{m}^{2}\right)$ ) were tested based on the current guidelines [19]. A GS decrease was defined as $<26 \mathrm{~kg}$ in men and $<18 \mathrm{~kg}$ in women [19]. An SMI decrease was defined as $<7.0 \mathrm{~kg} / \mathrm{m}^{2}$ in men and $<5.7 \mathrm{~kg} / \mathrm{m}^{2}$ in women [19].

\subsection{Primary Outcome Measure of This Study}

The primary endpoint of this study was the first incidence of CHEs [20-24]. CHEs included the incidence of hepatic decompensation, new-onset or deterioration of ascites, variceal bleeding, acute-on-chronic liver failure, HE, or HCC. During the observation period, any CHE was registered. 
Patients were followed from the baseline measurement of sarcopenia-related markers (i.e., GS, SMI, and SF36) until the first incidence of CHEs, death, or until the end of follow-up.

\subsection{Physical Component Summary Score and Mental Component Summary Score on the SF36}

The study subjects were asked to complete the Japanese version of the SF36, a globally accepted assessment tool for patient QOL [41,42]. The SF36 consists of a total of 36 items classified into eight item scales: physical functioning (PF), role physical (RP), bodily pain (BP), general health perception (GH), vitality (VT), social functioning (SF), role emotion (RE), and mental health (MH) [43]. The physical component summary (PCS summary score for PF, RP, BP, and GH) and the mental component summary (MCS summary score for VT, SF, RE, and MH) were analyzed in this study [43]. A higher PCS and higher MCS indicate a favorable health status. Patients with overt encephalopathy were not included in this study.

\subsection{Statistical Analyses}

In the univariate analyses of factors related to the incidence of CHEs, the median value for each factor was chosen to divide the study cohort into the two categorical groups and was then treated as a nominal variable. Factors with values of $p<0.01$ on univariate analysis were entered into the multivariate Cox hazard model considering the number of CHEs. Survival curves were made by the Kaplan-Meier method and compared by the log-rank test. Data were shown as median value with interquartile range (IQR). The level of statistical significance was set at $p<0.05$ by the statistical analysis software (JMP 14 (SAS Institute Inc., Cary, NC)).

\section{Results}

\subsection{Baseline Characteristics}

The demographic and clinical characteristics of the analyzed subjects $(n=411)$ are presented in Table 1. The study cohort included 199 men and 212 women with the median age (IQR) of $64(54,71)$ years. The median follow-up duration was 3.55 years. Regarding liver disease etiologies, patients were predominantly HCV (258/411 (62.8\%)). LC was seen in 160 patients (38.9\%). Among the LC patients, 121 were Child-Pugh A, 33 were Child-Pugh B, and 6 were Child-Pugh C. The median (IQR) GS values were $34.3 \mathrm{~kg}(28.65,41.2 \mathrm{~kg})$ in men and $20.95 \mathrm{~kg}(17.5375,23.875 \mathrm{~kg})$ in women. Among the men, 29 patients $(14.6 \%)$ had a GS decrease, while among the women, 60 patients $(28.3 \%)$ had a GS decrease as defined by the current Japanese criteria [19]. The median (IQR) SMI values were $7.50 \mathrm{~kg} / \mathrm{m}^{2}$ $\left(6.97,7.98 \mathrm{~kg} / \mathrm{m}^{2}\right)$ in men and $5.92 \mathrm{~kg} / \mathrm{m}^{2}\left(5.46,6.46 \mathrm{~kg} / \mathrm{m}^{2}\right)$ in women. Among the men, 52 patients (26.1\%) had an SMI decrease, while among the men, 73 patients (34.4\%) had an SMI decrease as defined by the current Japanese criteria [19]. The median (IQR) PCS and MCS were $51.1(41.6,54.3)$ and 52.3 $(44.2,58.7)$, respectively. 
Table 1. Baseline characteristics $(n=411)$.

\begin{tabular}{|c|c|}
\hline Variable & $\begin{array}{c}\text { Number or } \\
\text { Median Value (IQR) }\end{array}$ \\
\hline Age (years) & $64(54,71)$ \\
\hline Sex, male/female & $199 / 212$ \\
\hline Body mass index $\left(\mathrm{kg} / \mathrm{m}^{2}\right)$ & $22.6(20.5,25.5)$ \\
\hline $\begin{array}{c}\text { Liver disease etiology } \\
(\mathrm{HCV} / \mathrm{HBV} / \mathrm{HCV} \text { and } \mathrm{HBV} / \mathrm{NBNC})\end{array}$ & $258 / 59 / 8 / 86$ \\
\hline Grip strength $(\mathrm{kg}$, male $)$ & $34.3(28.65,41.2)$ \\
\hline Grip strength (kg, female) & $20.95(17.5375,23.875)$ \\
\hline Presence of LC, yes/no & $160 / 251$ \\
\hline Total bilirubin (mg/dL) & $0.8(0.6,1.0)$ \\
\hline Serum albumin $(\mathrm{g} / \mathrm{dL})$ & $4.2(3.9,4.5)$ \\
\hline Prothrombin time (\%) & $90.0(80.2,98.0)$ \\
\hline Platelet count $\left(\times 10^{4} / \mathrm{mm}^{3}\right)$ & $16.6(11.8,21.1)$ \\
\hline $\mathrm{SMI}\left(\mathrm{kg} / \mathrm{m}^{2}\right.$, male $)$ & $7.50(6.97,7.98)$ \\
\hline SMI $\left(\mathrm{kg} / \mathrm{m}^{2}\right.$, female $)$ & $5.92(5.46,6.46)$ \\
\hline Physical component summary score & $51.1(41.6,54.3)$ \\
\hline Mental component summary score & $52.3(44.2,58.7)$ \\
\hline AST $(\mathrm{IU} / \mathrm{L})$ & $27(21,40)$ \\
\hline ALT (IU/L) & $24(16,41)$ \\
\hline $\mathrm{HbA1c}$ (NGSP) & $5.7(5.4,6.0)$ \\
\hline eGFR $\left(\mathrm{ml} / \mathrm{min} / 1.73 \mathrm{~m}^{2}\right)$ & $82(71,95)$ \\
\hline Alpha-fetoprotein (ng/mL) & $3.4(2.3,5.8)$ \\
\hline BTR & $5.64(4.31,6.835)$ \\
\hline
\end{tabular}

AST, aspartate aminotransferase; ALT, alanine aminotransferase; BTR, branched-chain amino acid to tyrosine ratio; eGFR, estimated glomerular filtration rate; $\mathrm{HBV}$, hepatitis $\mathrm{B}$ virus; $\mathrm{HCV}$, hepatitis $\mathrm{C}$ virus; $\mathrm{IQR}$, interquartile range; LC, liver cirrhosis; NBNC, non-B and non-C; NGSP, National Glycohemoglobin Standardization Program; SMI, skeletal muscle index.

\subsection{Cumulative Incidences of CHEs for All Cases}

The first incidence of CHEs was our primary outcome measure. During the follow-up period, 62 patients (15.1\%) had the first incidence of CHEs. Of them, HCC development accounted for $54.8 \%$ (34 patients). None of the patients underwent liver transplantation. The 1-, 3-, and 5-year cumulative incidences of CHEs were $6.76 \%, 14.98 \%$, and $17.55 \%$, respectively (Figure $1 \mathrm{~A}$ ).
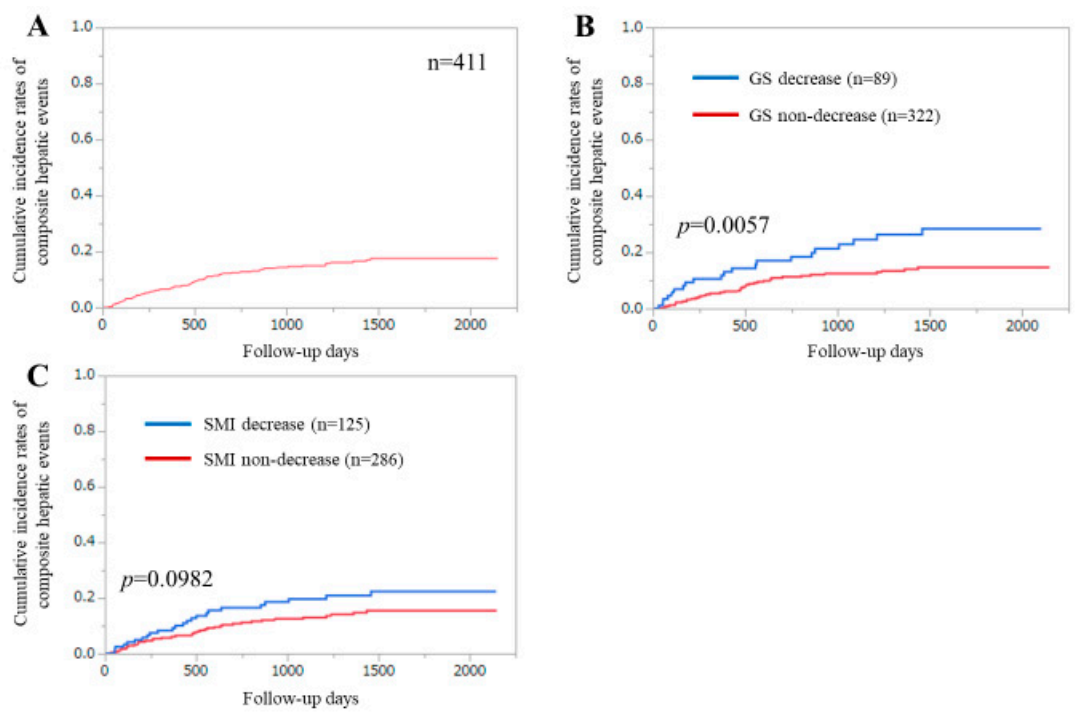

Figure 1. (A) Cumulative incidence of composite hepatic events (CHEs) for all cases $(n=411)$. (B) Cumulative incidence of CHEs stratified by grip strength (GS). (C) Cumulative incidence of CHEs stratified by skeletal muscle mass index (SMI). 


\subsection{Cumulative Incidences of CHEs for All Cases Stratified by GS or SMI}

The 1-, 3-, and 5-year cumulative incidences of CHEs were $10.57 \%, 24.51 \%$, and $28.44 \%$ in the GS decrease group and $5.74 \%, 12.44 \%$, and $14.62 \%$ in the GS non-decrease group ( $p=0.0057$ ) (Figure 1B).

The 1-, 3-, and 5-year cumulative incidences of CHEs were $8.33 \%, 19.65 \%$, and $22.34 \%$ in the SMI decrease group and $6.09 \%, 12.99 \%$, and $15.47 \%$ in the SMI non-decrease group ( $p=0.0982$ ) (Figure 1C).

We further divided the study subjects into four groups: (1) patients with GS decrease and SMI decrease (sarcopenia, $n=52$ ); (2) patients with GS decrease and SMI non-decrease (dynapenia, $n=37$ ); (3) patients with GS non-decrease and SMI decrease (presarcopenia, $n=73$ ); and (4) patients with GS non-decrease and SMI non-decrease (control, $n=249$ ). The cumulative incidences of CHEs among the four groups reached significance $(p=0.0254)$ (Figure 2).

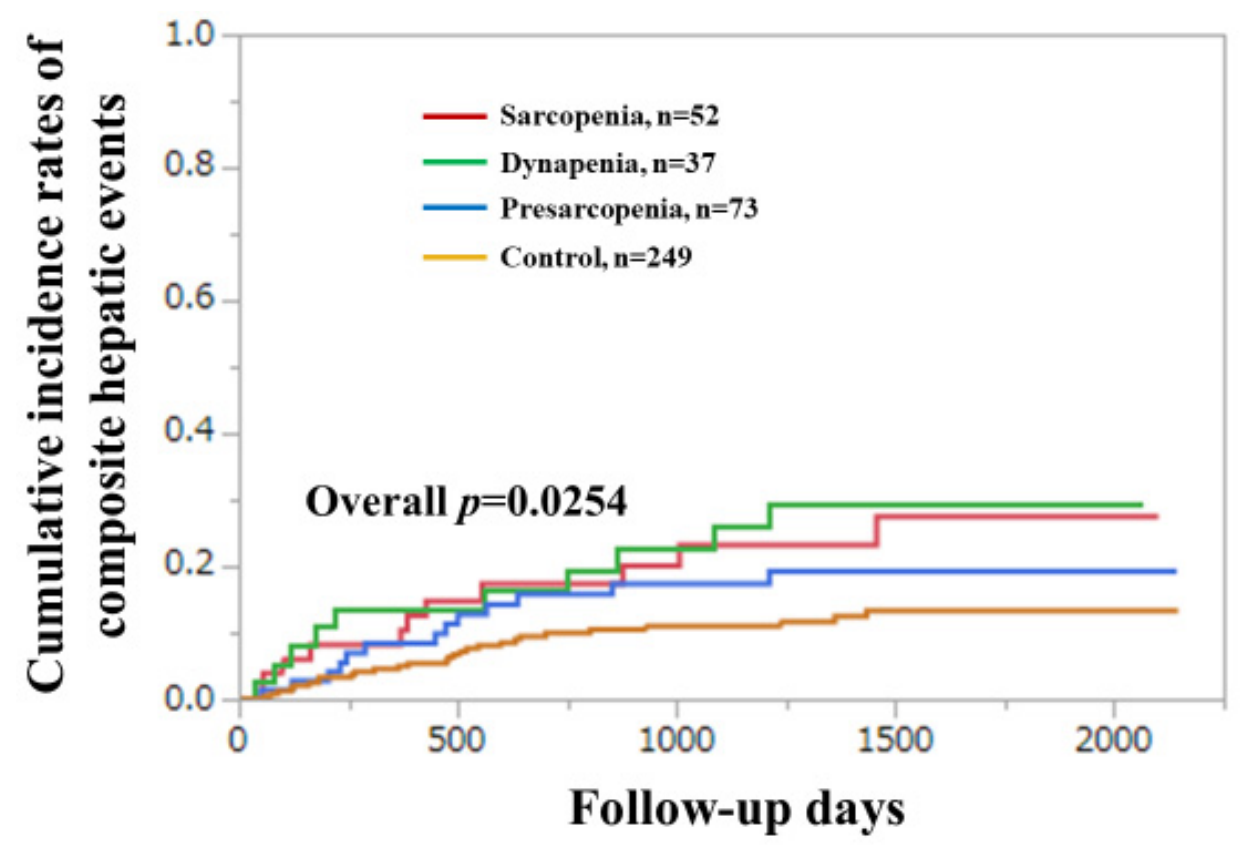

Figure 2. Cumulative incidence of composite hepatic events (CHEs) among the four groups. Sarcopenia indicates grip strength (GS) decrease and skeletal muscle mass index (SMI) decrease. Dynapenia indicates a GS decrease and SMI indicates a non-decrease. Presarcopenia indicates a GS non-decrease and an SMI decrease. Control indicates a GS non-decrease and SMI indicates a non-decrease.

\subsection{Uni- and Multivariate Analyses of Factors Linked to the Incidence of CHEs}

The univariate analysis of factors linked to the incidence of CHEs revealed that seven had values of $p<0.01$ : age $\geq 64$ years $(p<0.0001)$, GS decrease $(p=0.0057)$, serum albumin $\geq 4.2 \mathrm{~g} / \mathrm{dL}$ $(p<0.0001)$, prothrombin time (PT) $\geq 90.0 \%(p<0.0001)$, platelet count $\geq 16.6 \times 10^{4} / \mathrm{mm}^{3}(p<0.0001)$, aspartate aminotransferase $\geq 27 \mathrm{IU} / \mathrm{L}(p=0.0008)$, and branched-chain amino acid to tyrosine ratio $\geq 5.64(p<0.0001)$ (Table 2). Multivariate analysis of the seven factors showed that GS decrease $(p=0.0350)$ and $\mathrm{PT} \geq 90.0 \%$ ( $p=0.0293)$ were significant factors associated with the incidence of CHEs (Table 2). Hazard ratios (HRs) and 95\% confidence intervals (CIs) for these items are shown in Table 2. The presence of LC was not included in the analysis because it can be a confounding factor for liver functional parameters such as total bilirubin, serum albumin, and PT. 
Table 2. Univariate and multivariate analyses of factors contributing to the incidence of composite hepatic events (cutoff value for GS decrease in men, $26 \mathrm{~kg}$ ).

\begin{tabular}{|c|c|c|c|c|}
\hline \multirow{2}{*}{ Variable } & \multirow{2}{*}{$\begin{array}{c}\text { Univariate } \\
p \text { Value }\end{array}$} & \multicolumn{3}{|c|}{ Multivariate Analysis } \\
\hline & & HR & $95 \% \mathrm{CI}$ & $p$ Value \\
\hline Age $\geq 64$ years & $<0.0001$ & 1.160 & $0.898-1.497$ & 0.2559 \\
\hline Sex & 0.1137 & & & \\
\hline Body mass index $\geq 22.6 \mathrm{~kg} / \mathrm{m}^{2}$ & 0.5752 & & & \\
\hline GS decrease & 0.0057 & 1.413 & $1.025-1.920$ & 0.0350 \\
\hline SMI decrease & 0.0982 & & & \\
\hline Total bilirubin $\geq 0.8 \mathrm{mg} / \mathrm{dL}$ & 0.0232 & & & \\
\hline Serum albumin $\geq 4.2 \mathrm{~g} / \mathrm{dL}$ & $<0.0001$ & 0.969 & $0.748-1.251$ & 0.8081 \\
\hline Prothrombin time $\geq 90.0 \%$ & $<0.0001$ & 0.740 & $0.564-0.970$ & 0.0293 \\
\hline Platelet count $\geq 16.6 \times 10^{4} / \mathrm{mm}^{3}$ & $<0.0001$ & 0.994 & $0.760-1.299$ & 0.9628 \\
\hline PCS $\geq 51.1$ & 0.0318 & & & \\
\hline MCS $\geq 52.3$ & 0.7995 & & & \\
\hline $\mathrm{AST} \geq 27 \mathrm{IU} / \mathrm{L}$ & 0.0008 & 1.190 & $0.934-1.515$ & 0.1582 \\
\hline $\mathrm{ALT} \geq 24 \mathrm{IU} / \mathrm{L}$ & 0.0494 & & & \\
\hline Alpha fetoprotein $\geq 3.4 \mathrm{ng} / \mathrm{mL}$ & 0.1106 & & & \\
\hline $\mathrm{HbA} 1 \mathrm{c}(\mathrm{NGSP}) \geq 5.7$ & 0.0868 & & & \\
\hline $\mathrm{eGFR} \geq 82 \mathrm{~mL} / \mathrm{min} / 1.73 \mathrm{~m}^{2}$ & 0.3744 & & & \\
\hline $\mathrm{BTR} \geq 5.64$ & $<0.0001$ & 0.988 & $0.770-1.271$ & 0.9234 \\
\hline
\end{tabular}

ALT, alanine aminotransferase; AST, aspartate aminotransferase; BTR, branched-chain amino acid to tyrosine ratio; $\mathrm{CI}$, confidence interval; eGFR, estimated glomerular filtration rate; GS, grip strength; HR, hazard ratio; MCS, mental component summary score; NGSP, National Glycohemoglobin Standardization Program; PCS, physical component summary score; SMI, skeletal muscle mass index.

\subsection{Subgroup Analysis 1. Cumulative Incidences of CHEs for LC Cases and Non-LC Cases Stratified by GS and SMI}

Among the LC cases $(n=160)$, the difference in the cumulative incidences of CHEs between the GS decrease and non-decrease groups did not reach significance $(p=0.2704)$, nor did that between the SMI decrease and non-decrease groups $(p=0.5893)$ (Figure 3A,B).
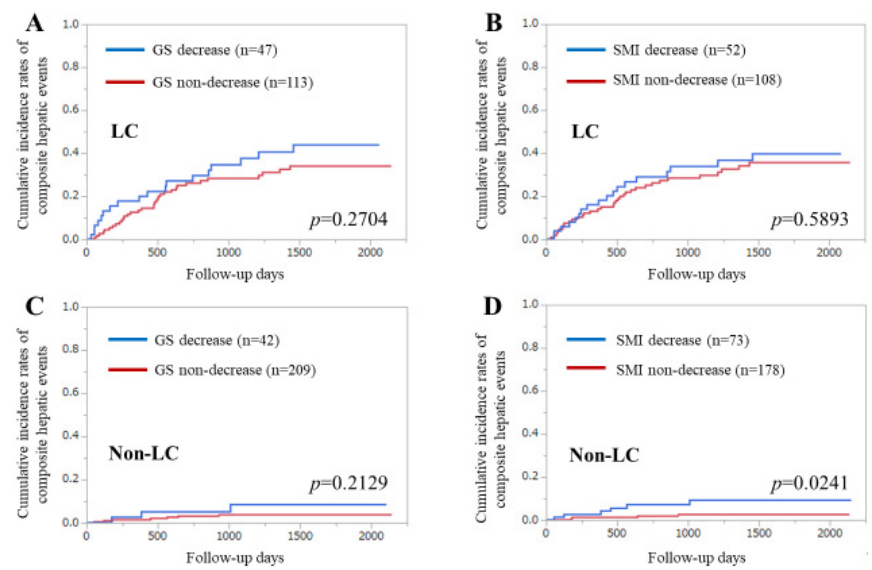

Figure 3. Subgroup analyses by liver cirrhosis (LC) status. (A) Cumulative incidence of composite hepatic events (CHEs) stratified by grip strength (GS) in LC patients. (B) Cumulative incidences of CHEs stratified by skeletal muscle mass index (SMI) in LC patients. (C) Cumulative incidences of CHEs stratified by GS in non-LC patients. (D) Cumulative incidences of CHEs stratified by SMI in non-LC patients.

Among the non-LC cases ( $n=252)$, the difference in the cumulative incidences of CHEs between the GS decrease and GS non-decrease groups did not reach significance $(p=0.2129)$, while that between the SMI decrease and non-decrease groups reached significance $(p=0.0241)$ (Figure 3C,D). 
3.6. Subgroup Analysis 2. Cumulative Incidence Rates of CHEs for Male and Female Cases Stratified by GS and SMI

Among the men $(n=199)$, the difference in the cumulative incidences of CHEs between the GS decrease and non-decrease groups reached significance $(p=0.0095)$, while that between the SMI decrease and non-decrease groups was not significant $(p=0.1057)$ (Figure $4 \mathrm{~A}, \mathrm{~B})$.
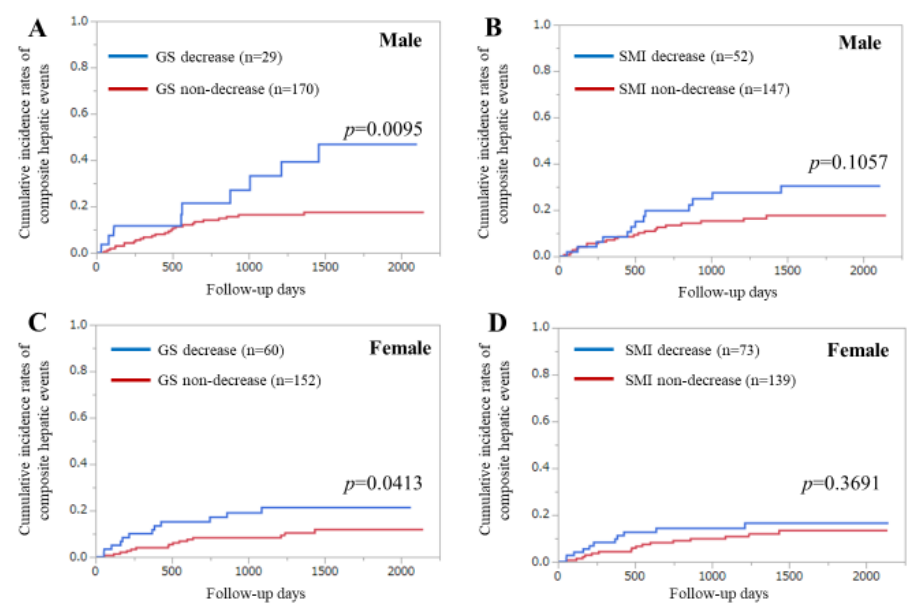

Figure 4. Subgroup analyses according to gender. (A) Cumulative incidence of CHEs stratified by GS in male. (B) Cumulative incidence of CHEs stratified by SMI in male. (C) Cumulative incidence of CHEs stratified by GS in female. (D) Cumulative incidence of CHEs stratified by SMI in female.

Among the women $(n=212)$, the difference in the cumulative incidences of CHEs between the GS decrease and non-decrease groups reached significance $(p=0.0413)$, while that between the SMI decrease and non-decrease groups did not reach significance $(p=0.3691)$ (Figure 4C,D).

3.7. Subgroup Analysis 3. Cumulative Incidence Rates of CHEs for Elderly Cases and Younger Cases Stratified by GS and SMI

Among the elderly cases ( $\geq 65$ years, $n=201)$, the difference in the cumulative incidences of CHEs between the GS decrease and non-decrease groups was not significant $(p=0.4363)$, while that between the SMI decrease and non-decrease groups was also not significant $(p=0.7522)$ (Figure $5 \mathrm{~A}, \mathrm{~B})$.
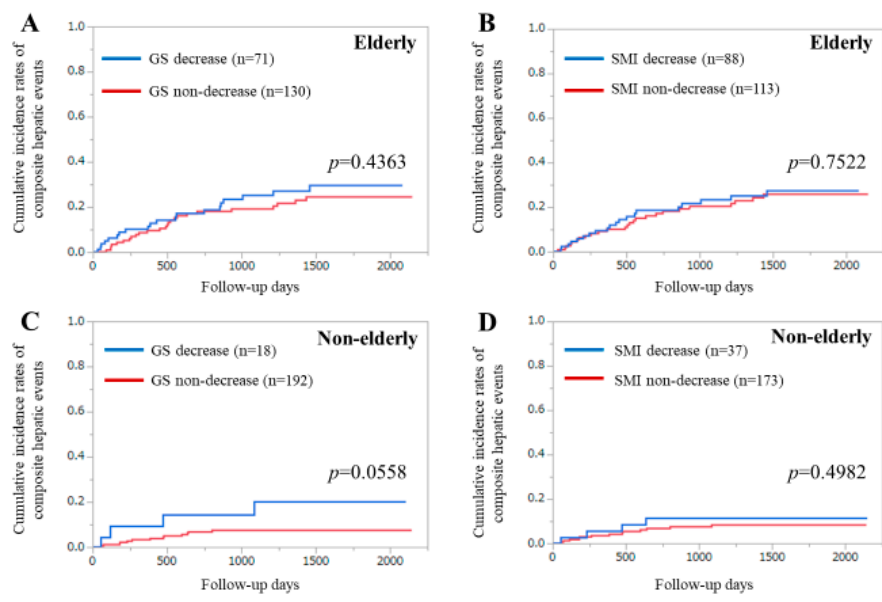

Figure 5. Subgroup analyses by age. (A) Cumulative incidence of composite hepatic events (CHEs) stratified by grip strength (GS) in patients aged 65 years or older. (B) Cumulative incidence of CHEs stratified by skeletal muscle mass index (SMI) in patients aged 65 years or older. (C) Cumulative incidence of CHEs stratified by GS in patients aged less than 65 years. (D) Cumulative incidence of CHEs stratified by SMI in patients aged less than 65 years. 
In younger cases ( $<65$ years, $n=210$ ), the difference in the cumulative incidences of CHEs between the GS decrease and non-decrease groups tended to be significant $(p=0.0558)$, while that between the SMI decrease and non-decrease groups did not reach significance $(p=0.4982)$ (Figure $5 C, D)$.

\subsection{Additional Analyses Using Different Cutoff Point of GS in Men ( $<28 \mathrm{~kg})$}

The Asian Working Group for Sarcopenia (AWGS) group recently revised the cutoff point of GS in men from $<26$ to $<28 \mathrm{~kg}$ (that in women remained $<18 \mathrm{~kg}$ ) [44]. Thus, we further analyzed the cohort using this revised cutoff point. The GS decreased in men increased from 29 to 44 . The difference in the cumulative incidences of CHEs between the GS decrease and non-decrease groups remained significant $(p=0.0047)$ (Figure 6A). The difference in the cumulative incidences of CHEs among the four groups (sarcopenia $(n=59)$, dynapenia $(n=45)$, presarcopenia $(n=66)$, and control $(n=241))$ also remained significant $(p=0.0329)$ (Figure 6B). Multivariate analysis of the seven factors determined that a GS decrease $(p=0.0460)$ and PT $(p=0.0310)$ were significant factors associated with the incidence of CHEs (Table 3). HRs and 95\% CIs for these items are shown in Table 3.

Table 3. Multivariate analyses of factors contributing to the incidence of composite hepatic events (cutoff value for GS decrease in men, $28 \mathrm{~kg}$ ).

\begin{tabular}{cccc}
\hline \multirow{2}{*}{ Variable } & \multicolumn{3}{c}{ Multivariate Analysis } \\
\cline { 2 - 4 } & HR & $\mathbf{9 5 \%}$ CI & $p$ Value \\
\hline Age $\geq 64$ years & 1.165 & $0.902-1.504$ & 0.2424 \\
GS decrease & 1.304 & $1.006-1.604$ & 0.0460 \\
Serum albumin $\geq 4.2 \mathrm{~g} / \mathrm{dL}$ & 0.954 & $0.737-1.233$ & 0.7208 \\
Prothrombin time $\geq 90.0 \%$ & 0.742 & $0.566-0.973$ & 0.0310 \\
Platelet count $\geq 16.6 \times 10^{4} / \mathrm{mm}^{3}$ & 0.999 & $0.766-1.305$ & 0.9952 \\
AST $\geq 27$ IU/L & 1.173 & $0.920-1.493$ & 0.1972 \\
BTR $\geq 5.64$ & 0.967 & $0.754-1.244$ & 0.7946 \\
\hline
\end{tabular}

AST, aspartate aminotransferase; BTR, branched-chain amino acid to tyrosine ratio; CI, confidence interval; GS, grip strength; $\mathrm{HR}$, hazard ratio.
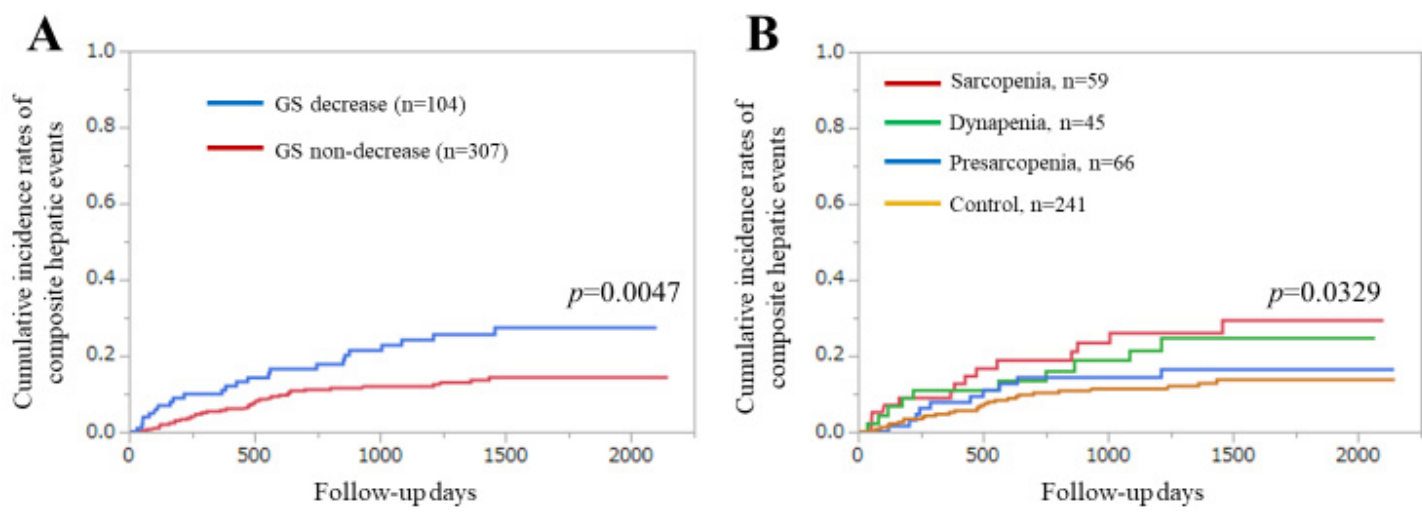

Figure 6. (A) Cumulative incidence of composite hepatic events (CHEs) stratified by grip strength (GS) for all cases (different cutoff point of GS in men, $<28 \mathrm{~kg}$ ). (B) Cumulative incidence of CHEs among the four groups. Sarcopenia indicates a GS decrease and skeletal muscle mass index (SMI) decrease. Dynapenia indicates a GS decrease and an SMI non-decrease. Presarcopenia indicates a GS non-decrease and an SMI decrease. Control indicates a GS non-decrease and an SMI non-decrease.

\section{Discussion}

To the best of our knowledge, this is the first study to elucidate the effect of sarcopenia-related factors on CHEs in patients with CLDs. Liver carcinogenesis, liver functional reserve-related factors, and portal hypertension-related factors appear to be well-established predictors for survival in CLDs [25-30]. Thus, we believe that the incidence of CHEs is an appropriate primary outcome measure. 
The decrease in patient QOL in CLDs tends to be frequently overlooked or unrecognized because patient QOL in CLDs can be compromised. In this study, SF36 data (PCS and MCS) were included in the analysis. One of major strengths in this study is its large sample size with GS, SMI, and SF36 data all available.

In our results, GS was an independent predictor for the incidence of CHEs in the multivariate analysis. When the GS cutoff in men was changed to $<28 \mathrm{~kg}$, similar results were obtained. In several subgroups, significant impacts of the GS decline on CHEs were found. Collectively, these results indicated that GS can be a useful marker for the incidence of CHEs in patients with CLDs. When we looked at the Kaplan-Meier curves shown in Figures 2 and 6B, we noticed that curves of the sarcopenia or dynapenia group were almost constantly above those of the presarcopenia or control group, which supports the impact of GS on CHEs in our analysis. Because a reduced muscle mass generally precedes a reduced muscle strength, dynapenia may have unique characteristics that can involve serious negative consequences [45]. Appropriate interventional strategies for CLD patients with GS decline should be recommended. While SMI was not a significant predictor of the incidence of CHEs, muscle mass appears to play a relatively minor role on the incidence of CHEs compared with muscle function.

A previous large observational study $(n=139,691)$ demonstrated that GS measurement is a simple, inexpensive risk-stratifying method for all-cause mortality, cardiovascular-related death, and cardiovascular disease [46]. In addition, a greater GS was significantly linked to a reduced risk of cancer mortality [47]. A previous report demonstrated that GS should be considered a vital sign useful for screening older as well as middle-aged adults [48]. A previous meta-analysis reported that objective measures of physical function (i.e., GS, walking speed, chair rising, and standing balance times) were predictive factors for all-cause mortality in elderly community-dwelling populations [49]. As muscle function reacts early to nutrition deprivation, GS can be a reliable marker for nutrition status [50,51]. These observations may be linked to our current results. Contrary to our expectations, PCS in the SF36 was not an independent predictor in our analysis, although it was significant in the univariate analysis. SF36 is a subjective assessment method of patient QOL and may have affected our results [43]. However, we believe that our results do not deny the importance of maintaining patient QOL in the management of CLDs.

The cutoff point of GS in men was recently revised from $<26$ to $<28 \mathrm{~kg}$ (that in women remains $<18 \mathrm{~kg}$ ) in the revised AWGS criteria [44]. About three decades have passed since sarcopenia was proposed by Rosenberg in 1989 as a condition in which skeletal muscle mass decreases with age [52]. Muscle atrophy undoubtedly develops with age [45]. For the past several decades, sarcopenia research has largely focused on muscle size [19]. However, studies in this field have progressed and emphasis has been placed on the qualitative evaluation of muscle and physical function as well as muscle mass. The diagnosis of sarcopenia has been made with many diseases and has significantly attracted attention, and sarcopenia has been recognized as an independent disease entity. Significant impacts of GS on CHEs in cases with a cutoff of $<26 \mathrm{~kg}$ in men and $<28 \mathrm{~kg}$ in men in the multivariate analyses suggests the prognostic robustness of GS on the incidence of CHEs in CLD patients. While reference values of GS may be revised in the future, it is necessary to re-examine the clinical significance of sarcopenia-related factors accordingly.

Several limitations must be acknowledged to this study. First, this single-center observational retrospective study should be acknowledged. Second, patients with massive ascites at baseline who potentially have a higher incidence of liver disease-related events were excluded due to a lack of BIA results, creating bias. Third, our follow-up period (median 3.55 years) was relatively short for the analysis, especially in non-LC patients because the number of expected CHEs is low in non-LC patients. Fourth, our cohort had highly heterogeneous patient populations including various liver disease etiologies and various stages of liver function, and several subgroup analyses had small case number of cohort (e.g., non-elderly GS decrease $(n=18)$ ). However, we believe the multivariate analysis reduced these biases. Finally, the impact of sarcopenia-related factors on overall survival (OS) was not analyzed 
in this study (beyond the scope of the current analysis). The impact of GS or other sarcopenia-related factors on OS in patients with CLDs should be fully examined in future studies. Consequently, caution must be exercised in the interpretation of our study data. Despite these limitations, our study results suggest that a GS decrease in CLDs was closely associated with the incidence of CHEs. In conclusion, GS can be an independent predictor for CHE development in patients with CLDs. Clinicians should be aware of the possibility of CHEs in CLD patients with a decreased GS.

Author Contributions: Data curation, K.Y., H.N., H.E., Y.I., N.I., N.A., T.N., and H.I.; supervision, H.I. and S.N.; writing—original draft, H.N.; writing—review and editing, K.Y., H.N., and H.E. All authors have read and agreed to the published version of the manuscript.

Funding: This research received no external funding.

Acknowledgments: The authors thank all medical staff in our hospital for their support. This work was partly supported by Hyogo Innovative Challenge, Hyogo College of Medicine, Japan.

Conflicts of Interest: The authors declare no conflict of interest.

\section{Abbreviations}

$\begin{array}{ll}\text { ALT } & \text { alanine aminotransferase } \\ \text { AWGS } & \text { Asian Working Group for Sarcopenia } \\ \text { BIA } & \text { bioimpedance analysis } \\ \text { BP } & \text { bodily pain } \\ \text { CHEs } & \text { composite hepatic events } \\ \text { CI } & \text { confidence interval } \\ \text { CLDs } & \text { chronic liver diseases } \\ \text { GH } & \text { general health perception } \\ \text { GS } & \text { grip strength } \\ \text { HCC } & \text { hepatocellular carcinoma } \\ \text { HCV } & \text { hepatitis C virus } \\ \text { HE } & \text { hepatic encephalopathy } \\ \text { HR } & \text { hazard ratio } \\ \text { LC } & \text { liver cirrhosis } \\ \text { MELD } & \text { Model for End-Stage Liver Disease } \\ \text { IQR } & \text { interquartile range } \\ \text { MCS } & \text { mental component summary score } \\ \text { MH } & \text { mental health } \\ \text { PCS } & \text { physical component summary score } \\ \text { PF } & \text { physical functioning } \\ \text { PT } & \text { prothrombin time } \\ \text { QOL } & \text { quality of life } \\ \text { RE } & \text { role emotion } \\ \text { RP } & \text { role physical } \\ \text { SF } & \text { social functioning } \\ \text { SF36 } & \text { 36-Item Short-Form Health Survey } \\ \text { SMI } & \text { skeletal muscle mass index } \\ \text { VT } & \text { vitality } \\ & \end{array}$

\section{References}

1. Tandon, P.; Raman, M.; Mourtzakis, M.; Merli, M. A practical approach to nutritional screening and assessment in cirrhosis. Hepatology 2017, 65, 1044-1057. [CrossRef] [PubMed]

2. Nishikawa, H.; Enomoto, H.; Ishii, A.; Iwata, Y.; Miyamoto, Y.; Ishii, N.; Yuri, Y.; Hasegawa, K.; Nakano, C.; Nishimura, T.; et al. Elevated serum myostatin level is associated with worse survival in patients with liver cirrhosis. J. Cachexia Sarcopenia Muscle 2017, 8, 915-925. [CrossRef] [PubMed]

3. Kim, G.; Kang, S.H.; Kim, M.Y.; Baik, S.K. Prognostic value of sarcopenia in patients with liver cirrhosis: A systematic review and meta-analysis. PLoS ONE 2017, 12, e0186990. [CrossRef] [PubMed] 
4. Meyer, F.; Valentini, L. Disease-Related Malnutrition and Sarcopenia as Determinants of Clinical Outcome. Visc. Med. 2019, 35, 282-291. [CrossRef] [PubMed]

5. Bunchorntavakul, C.; Reddy, K.R. Review article: Malnutrition/sarcopenia and frailty in patients with cirrhosis. Aliment. Pharmacol. Ther. 2020, 51, 64-77. [CrossRef] [PubMed]

6. Aby, E.S.; Saab, S. Frailty, sarcopenia, and malnutrition in cirrhotic patients. Clin. Liver Dis. 2019, 23, 589-605. [CrossRef]

7. Hayashi, F.; Matsumoto, Y.; Momoki, C.; Yuikawa, M.; Okada, G.; Hamakawa, E.; Kawamura, E.; Hagihara, A.; Toyama, M.; Fujii, H.; et al. Physical inactivity and insufficient dietary intake are associated with the frequency of sarcopenia in patients with compensated viral liver cirrhosis. Hepatol. Res. 2013, 43, 1264-1275. [CrossRef]

8. Ohashi, K.; Ishikawa, T.; Hoshi, A.; Suzuki, M.; Mitobe, Y.; Yamada, E.; Abeywickrama, H.M.; Seki, N.; Koyama, C.; Aoki, H.; et al. Relationship between sarcopenia and both physical activity and lifestyle in patients with chronic liver disease. J. Clin. Med. Res. 2018, 10, 920-927. [CrossRef]

9. Stenholm, S.; Tiainen, K.; Rantanen, T.; Sainio, P.; Heliövaara, M.; Impivaara, O.; Koskinen, S. Long-term determinants of muscle strength decline: Prospective evidence from the 22-year mini-Finland follow-up survey. J. Am. Geriatr. Soc. 2012, 60,77-85. [CrossRef]

10. Younossi, Z.M. Patient-reported outcomes and the economic effects of nonalcoholic fatty liver disease and nonalcoholic steatohepatitis: The value proposition. Hepatology 2018, 68, 2405-2412. [CrossRef]

11. Golfieri, L.; Gitto, S.; Morelli, M.C.; Pinna, A.D.; Grandi, S.; Andreone, P. Impact of hepatitis C virus infection on health-related quality of life before and after liver transplantation: A multidisciplinary point of view. Expert Rev. Anti. Infect. Ther. 2017, 15, 759-765. [CrossRef] [PubMed]

12. Younossi, Z.M.; Stepanova, M.; Younossi, I.; Pan, C.Q.; Janssen, H.L.A.; Papatheodoridis, G.; Nader, F. Long-term effects of treatment for chronic HBV infection on patient-reported outcomes. Clin. Gastroenterol Hepatol. 2018. [CrossRef] [PubMed]

13. Schramm, C.; Wahl, I.; Weiler-Normann, C.; Voigt, K.; Wiegard, C.; Glaubke, C.; Brähler, E.; Löwe, B.; Lohse, A.W.; Rose, M. Health-related quality of life, depression, and anxiety in patients with autoimmune hepatitis. J. Hepatol. 2014, 60, 618-624. [CrossRef]

14. Dyson, J.K.; Wilkinson, N.; Jopson, L.; Mells, G.; Bathgate, A.; Heneghan, M.A.; Neuberger, J.; Hirschfield, G.M.; Ducker, S.J.; UK-PBC Consortium; et al. The inter-relationship of symptom severity and quality of life in 2055 patients with primary biliary cholangitis. Aliment. Pharmacol. Ther. 2016, 44, 1039-1050. [CrossRef] [PubMed]

15. Nishikawa, H.; Enomoto, H.; Yoh, K.; Iwata, Y.; Sakai, Y.; Kishino, K.; Ikeda, N.; Takashima, T.; Aizawa, N.; Takata, R.; et al. Health-related quality of life in chronic liver diseases: A strong impact of hand grip strength. J. Clin. Med. 2018, 7, 553. [CrossRef]

16. Montano-Loza, A.J.; Duarte-Rojo, A.; Meza-Junco, J.; Baracos, V.E.; Sawyer, M.B.; Pang, J.X.; Beaumont, C.; Esfandiari, N.; Myers, R.P. Inclusion of sarcopenia within MELD (MELD-Sarcopenia) and the prediction of mortality in patients with cirrhosis. Clin. Transl. Gastroenterol. 2015, 6, e102. [CrossRef] [PubMed]

17. Marty, E.; Liu, Y.; Samuel, A.; Or, O.; Lane, J. A review of sarcopenia: Enhancing awareness of an increasingly prevalent disease. Bone 2017, 105, 276-286. [CrossRef]

18. Liguori, I.; Russo, G.; Aran, L.; Bulli, G.; Curcio, F.; Della-Morte, D.; Gargiulo, G.; Testa, G.; Cacciatore, F.; Bonaduce, D.; et al. Sarcopenia: Assessment of disease burden and strategies to improve outcomes. Clin. Interv. Aging 2018, 13, 913-927. [CrossRef]

19. Nishikawa, H.; Shiraki, M.; Hiramatsu, A.; Moriya, K.; Hino, K.; Nishiguchi, S. Japan Society of Hepatology guidelines for sarcopenia in liver disease (1st edition): Recommendation from the working group for creation of sarcopenia assessment criteria. Hepatol. Res. 2016, 46, 951-963. [CrossRef]

20. Wong, G.L.; Chan, H.L.; Tse, Y.K.; Yip, T.C.; Lam, K.L.; Lui, G.C.; Wong, V.W. Normal on-treatment ALT during antiviral treatment is associated with a lower risk of hepatic events in patients with chronic hepatitis B. J. Hepatol. 2018, 69, 793-802. [CrossRef]

21. Bihari, C.; Rastogi, A.; Sen, B.; Bhadoria, A.S.; Maiwall, R.; Sarin, S.K. Quantitative fibrosis estimation by image analysis predicts development of decompensation, composite events and defines event-free survival in chronic hepatitis B patients. Hum. Pathol. 2016, 55, 63-71. [CrossRef] [PubMed]

22. Patel, N.; Bichoupan, K.; Ku, L.; Yalamanchili, R.; Harty, A.; Gardenier, D.; Ng, M.; Motamed, D.; Khaitova, V.; Bach, N.; et al. Hepatic decompensation/serious adverse events in post-liver transplantation recipients on sofosbuvir for recurrent hepatitis C virus. World J. Gastroenterol. 2016, 22, 2844-2854. [CrossRef] [PubMed] 
23. Muto, Y.; Sato, S.; Watanabe, A.; Moriwaki, H.; Suzuki, K.; Kato, A.; Kato, M.; Nakamura, T.; Higuchi, K.; Nishiguchi, S.; et al. Long-Term Survival Study Group. Effects of oral branched-chain amino acid granules on event-free survival in patients with liver cirrhosis. Clin. Gastroenterol. Hepatol. 2005, 3, 705-713. [CrossRef]

24. Olsson, R.; Boberg, K.M.; de Muckadell, O.S.; Lindgren, S.; Hultcrantz, R.; Folvik, G.; Bell, H.; Gangsøy-Kristiansen, M.; Matre, J.; Rydning, A.; et al. High-dose ursodeoxycholic acid in primary sclerosing cholangitis: A 5-year multicenter, randomized, controlled study. Gastroenterology 2005, 129, 1464-1472. [CrossRef]

25. Tsochatzis, E.A.; Bosch, J.; Burroughs, A.K. Liver cirrhosis. Lancet 2014, 383, 1749-1761. [CrossRef]

26. European Association for the Study of the Liver. EASL Clinical Practice Guidelines: Management of hepatocellular carcinoma. J. Hepatol. 2018, 69, 182-236. [CrossRef]

27. European Association for the Study of the Liver. EASL Clinical Practice Guidelines for the management of patients with decompensated cirrhosis. J Hepatol. 2018, 69, 406-460. [CrossRef]

28. Heimbach, J.K.; Kulik, L.M.; Finn, R.S.; Sirlin, C.B.; Abecassis, M.M.; Roberts, L.R.; Zhu, A.X.; Murad, M.H.; Marrero, J.A. AASLD guidelines for the treatment of hepatocellular carcinoma. Hepatology 2018, 67, 358-380. [CrossRef]

29. Fukui, H.; Saito, H.; Ueno, Y.; Uto, H.; Obara, K.; Sakaida, I.; Shibuya, A.; Seike, M.; Nagoshi, S.; Segawa, M.; et al. Evidence-based clinical practice guidelines for liver cirrhosis 2015. J. Gastroenterol. 2016, 51, 629-650. [CrossRef]

30. Kokudo, N.; Takemura, N.; Hasegawa, K.; Takayama, T.; Kubo, S.; Shimada, M.; Nagano, H.; Hatano, E.; Izumi, N.; Kaneko, S.; et al. Clinical practice guidelines for hepatocellular carcinoma: The Japan Society of Hepatology 2017 (4th JSH-HCC guidelines) 2019 update. Hepatol. Res. 2019, 49, 1109-1113. [CrossRef]

31. Lanz, J.; Kim, W.K.; Walther, T.; Burgdorf, C.; Möllmann, H.; Linke, A.; Redwood, S.; Thilo, C.; Hilker, M.; Joner, M.; et al. Safety and efficacy of a self-expanding versus a balloon-expandable bioprosthesis for transcatheter aortic valve replacement in patients with symptomatic severe aortic stenosis: A randomised non-inferiority trial. Lancet 2019, 394, 1619-1628. [CrossRef]

32. Vranckx, P.; Valgimigli, M.; Eckardt, L.; Tijssen, J.; Lewalter, T.; Gargiulo, G.; Batushkin, V.; Campo, G.; Lysak, Z.; Vakaliuk, I.; et al. Edoxaban-based versus vitamin K antagonist-based antithrombotic regimen after successful coronary stenting in patients with atrial fibrillation (ENTRUST-AF PCI): A randomised, open-label, phase 3b trial. Lancet 2019, 394, 1335-1343. [CrossRef]

33. Iglesias, J.F.; Muller, O.; Heg, D.; Roffi, M.; Kurz, D.J.; Moarof, I.; Weilenmann, D.; Kaiser, C.; Tapponnier, M.; Stortecky, S.; et al. Biodegradable polymer sirolimus-eluting stents versus durable polymer everolimus-eluting stents in patients with ST-segment elevation myocardial infarction (BIOSTEMI): A single-blind, prospective, randomised superiority trial. Lancet 2019, 394, 1243-1253. [CrossRef]

34. Kudo, M.; Zheng, R.Q.; Kim, S.R.; Okabe, Y.; Osaki, Y.; Iijima, H.; Itani, T.; Kasugai, H.; Kanematsu, M.; Ito, K.; et al. Diagnostic accuracy of imaging for liver cirrhosis compared to histologically proven liver cirrhosis. A multicenter collaborative study. Intervirology 2008, 51, 17-26. [CrossRef] [PubMed]

35. Zarski, J.P.; Sturm, N.; Guechot, J.; Paris, A.; Zafrani, E.S.; Asselah, T.; Boisson, R.C.; Bosson, J.L.; Guyader, D.; Renversez, J.C.; et al. Comparison of nine blood tests and transient elastography for liver fibrosis in chronic hepatitis C: The ANRS HCEP-23 study. J. Hepatol. 2012, 56, 55-62. [CrossRef] [PubMed]

36. Tsochatzis, E.A.; Gurusamy, K.S.; Ntaoula, S.; Cholongitas, E.; Davidson, B.R.; Burroughs, A.K. Elastography for the diagnosis of severity of fibrosis in chronic liver disease: A meta-analysis of diagnostic accuracy. J. Hepatol. 2011, 54, 650-659. [CrossRef]

37. Kumada, H.; Okanoue, T.; Onji, M.; Moriwaki, H.; Izumi, N.; Tanaka, E.; Chayama, K.; Sakisaka, S.; Takehara, T.; Oketani, M.; et al. Guidelines for the treatment of chronic hepatitis and cirrhosis due to hepatitis C virus infection for the fiscal year 2008 in Japan. Hepatol. Res. 2010, 40, 8-13. [CrossRef]

38. Kappus, M.R.; Mendoza, M.S.; Nguyen, D.; Medici, V.; McClave, S.A. Sarcopenia in Patients with Chronic Liver Disease: Can It Be Altered by Diet and Exercise? Curr. Gastroenterol. Rep. 2016, 18, 43. [CrossRef]

39. Kokudo, N.; Hasegawa, K.; Akahane, M.; Igaki, H.; Izumi, N.; Ichida, T.; Uemoto, S.; Kaneko, S.; Kawasaki, S.; $\mathrm{Ku}, \mathrm{Y}$.; et al. Evidence-based Clinical Practice Guidelines for Hepatocellular Carcinoma: The Japan Society of Hepatology 2013 update (3rd JSH-HCC Guidelines). Hepatol. Res. 2015. [CrossRef]

40. Omata, M.; Cheng, A.L.; Kokudo, N.; Kudo, M.; Lee, J.M.; Jia, J.; Tateishi, R.; Han, K.H.; Chawla, Y.K.; Shiina, S.; et al. Asia-Pacific clinical practice guidelines on the management of hepatocellular carcinoma: A 2017 update. Hepatol. Int. 2017, 11, 317-370. [CrossRef] 
41. Mikdashi, J. Measuring and monitoring health-related quality of life responsiveness in systemic lupus erythematosus patients: Current perspectives. Patient Relat. Outcome Meas. 2018, 9, 339-343. [CrossRef] [PubMed]

42. Behboodi, M.Z.; Fereidooni, B.; Saffari, M.; Montazeri, A. Measures of health-related quality of life in PCOS women: A systematic review. Int. J. Womens Health. 2018, 10, 397-408. [CrossRef]

43. Fukuhara, S.; Ware, J.E., Jr.; Kosinski, M.; Wada, S.; Gandek, B. Psychometric and clinical tests of validity of the Japanese SF-36 Health Survey. J. Clin. Epidemiol. 1998, 51, 1045-1053. [CrossRef]

44. Chen, L.K.; Woo, J.; Assantachai, P.; Auyeung, T.W.; Chou, M.Y.; Iijima, K.; Jang, H.C.; Kang, L.; Kim, M.; Kim, S.; et al. Asian Working Group for Sarcopenia: 2019 Consensus Update on Sarcopenia Diagnosis and Treatment. J. Am. Med. Dir. Assoc. 2020. [CrossRef]

45. Clark, B.C.; Manini, T.M. What is dynapenia? Nutrition 2012, 28, 495-503. [CrossRef] [PubMed]

46. Leong, D.P.; Teo, K.K.; Rangarajan, S.; Lopez-Jaramillo, P.; Avezum, A., Jr.; Orlandini, A.; Seron, P.; Ahmed, S.H.; Rosengren, A.; Kelishadi, R.; et al. Prognostic value of grip strength: Findings from the Prospective Urban Rural Epidemiology (PURE) study. Lancet 2015, 386, 266-273. [CrossRef]

47. García-Hermoso, A.; Ramírez-Vélez, R.; Peterson, M.D.; Lobelo, F.; Cavero-Redondo, I.; Correa-Bautista, J.E.; Martínez-Vizcaíno, V. Handgrip and knee extension strength as predictors of cancer mortality: A systematic review and meta-analysis. Scand. J. Med. Sci. Sports 2018, 28, 1852-1858. [CrossRef]

48. Bohannon, R.W. Hand-grip dynamometry predicts future outcomes in aging adults. J. Geriatr. Phys. Ther. 2008, 31, 3-10. [CrossRef]

49. Cooper, R.; Kuh, D.; Hardy, R. Mortality Review Group; FALCon and HALCyon Study Teams. Objectively measured physical capability levels and mortality: Systematic review and meta-analysis. BMJ 2010, $341, \mathrm{c} 4467$.

50. Norman, K.; Stobäus, N.; Gonzalez, M.C.; Schulzke, J.D.; Pirlich, M. Hand grip strength: Outcome predictor and marker of nutritional status. Clin. Nutr. 2011, 30, 135-142. [CrossRef]

51. Knudsen, A.W.; Naver, A.; Bisgaard, K.; Nordgaard-Lassen, I.; Becker, U.; Krag, A.; Slinde, F. Nutrition impact symptoms, handgrip strength and nutritional risk in hospitalized patients with gastroenterological and liver diseases. Scand J. Gastroenterol. 2015, 50, 1191-1198. [CrossRef]

52. Rosenberg, I. Summary comments: Epidemiological and methodological problems in determining nutritional status of older persons. Am. J. Clin. Nutr. 1989, 50, 1231-1233. [CrossRef] 